\title{
The Gastric Emptying Study with Oatmeal: Reference Range and Reproducibility as a Function of Age and Sex
}

\author{
William C. Klingensmith III, Katherine L. Rhea, Elizabeth A. Wainwright, and Orlin Woodie Hopper \\ Department of Radiology, Porter Hospital, Denver, Colorado
}

This study evaluated the reference range and reproducibility of the gastric emptying study with oatmeal as a function of age and sex. Methods: Twenty-four healthy subjects, 12 men and 12 women, categorized into 3 age groups, 20-40, 40-60, and 60-80 y, were studied twice, $1 \mathrm{~d}$ apart, with instant oatmeal labeled with $99 \mathrm{~m}$ Tc-sulfur colloid. Imaging was performed in the upright position using the left anterior oblique (LAO), right posterior oblique (RPO), anterior, and posterior projections. One-minute digital images acquired every $15 \mathrm{~min}$ for $60 \mathrm{~min}$ were used to calculate a simple half-time of emptying. Results: A strong correlation was found among half-times of gastric emptying calculated from the anterior projection, LAO projection, anterior-posterior geometric mean, and LAO-RPO geometric mean $(P<0.01)$. A significant inverse correlation was found between increasing age and decreasing half-time of emptying in men and women $(P<0.05)$. A reference range of $10-60 \mathrm{~min}$ is suggested for 20 - to 40 -y-old patients, $10-40 \mathrm{~min}$ for 40 - to $60-y$-olds, and $10-30$ min for 60 - to 80 -y-olds. Halftimes of emptying tended to be longer for women than for men (not statistically significant). There was a large variation between the first and second studies, with a trend toward decreasing variation with increasing age in both men and women. In repeated studies, a reference range of variation of up to $30 \mathrm{~min}$ is suggested for 20 - to $40-\mathrm{y}$-old patients, up to $20 \mathrm{~min}$ for 40 - to $60-\mathrm{y}$-olds, and up to $15 \mathrm{~min}$ for $60-$ to $80-\mathrm{y}-$ olds. Conclusion: The reference range for half-time of gastric emptying with instant oatmeal decreases with increasing age in both men and women. Test-retest variation is relatively large and tends to decrease with increasing age in both men and women. Data from either the LAO projection or the anteriorposterior geometric mean are acceptable for calculating the half-time of gastric emptying.

Key Words: gastric emptying; $99 \mathrm{~m}$ Tc-sulfur colloid in instant oatmeal; normal range; reproducibility

J Nucl Med Technol 2010; 38:186-190 DOI: $10.2967 /$ jnmt.110.077065

Received Mar. 16, 2010; revision accepted Jul. 20, 2010.

For correspondence or reprints contact: William C. Klingensmith III, University of Colorado School of Medicine, 4720 East Oxford Ave., Englewood, CO 80113.

E-mail: bill.klingensmith@mac.com

COPYRIGHT @ 2010 by the Society of Nuclear Medicine, Inc. he gastric emptying study was first reported in 1966 by Griffith et al. (1). Since its introduction, numerous variations in the multiple parameters involved in performing the study have been reported. The parameters that have received the most attention are patient preparation, meal composition, meal radiolabel, patient position, imaging projection, duration of study, and data analysis $(2,3)$. However, the lack of a nonradioactive reference standard makes it difficult to determine the relative merits of the many reported variations in these parameters. The end result is that most institutions use a relatively unique protocol that can be considered a local favorite, but one that does not have a scientifically determined reference range.

In 2000, Tougas et al. reported reference values for 123 healthy subjects from 11 centers using a standardized protocol (4). The protocol specifies a meal of scrambled egg substitute equivalent to 2 eggs, 2 slices of bread, strawberry jam, and water with an overall caloric value of $255 \mathrm{kcal}$. The meal is labeled by cooking the egg substitute with ${ }^{99 \mathrm{~m}} \mathrm{Tc}-$ sulfur colloid. Patients are imaged in the upright position in the anterior and posterior projections at $0,1,2$, and $4 \mathrm{~h}$. Gastric retention greater than the 95th percentile was set as the upper limit of normal at each imaging time, with emphasis on the 4-h value. Partly because the reference range of this protocol has been well established, this protocol has been recommended for adoption by the American Neurogastroenterology and Motility Society and the Society of Nuclear Medicine (5,6).

In general, a protocol should be as simple as possible without sacrificing accuracy. A recent report raised 2 concerns about the lengthy and relatively complex Tougas protocol (7). First, the report compared a relatively simple oatmeal test meal and a scrambled egg test meal. Although the Tougas meal is more complex than a scrambled egg, its main ingredient is egg. The study found a high degree of intrapatient correlation between the gastric emptying times with the 2 meals, suggesting similar information content.

Second, the report documented that approximately $75 \%$ of patients have overlap of the stomach and colon in both the anterior and the left anterior oblique (LAO) projections. 
Because the normal transit time of the small bowel ranges from $15 \mathrm{~min}$ to $5 \mathrm{~h}$, it is possible that a significant number of counts in the gastric region of interest at $4 \mathrm{~h}$ in the Tougas protocol will actually come from the colon.

Although the gastric emptying study with instant oatmeal has the advantage of simplicity, the reference range and test-retest reproducibility have not been published. The present study evaluated the reference range and reproducibility of the gastric emptying study using ${ }^{99 \mathrm{~m}} \mathrm{Tc}$-sulfur colloid labeled instant oatmeal in 12 healthy men and 12 healthy women with a wide age range.

\section{MATERIALS AND METHODS}

\section{Subject Population}

Twelve healthy men and 12 healthy women equally distributed into 3 age groups-20-40, 40-60, and 60-80 ywere recruited and paid to participate in the study. Subjects with a history of gastrointestinal surgery, diabetes, or use of medications that might affect gastric motility and emptying, such as erythromycin and narcotics, were excluded. Also, subjects who were significantly underweight or overweight (body mass index $[\mathrm{BMI}]<18$ or $>28$ ) or had a history of an eating disorder were excluded. Pregnancy was an exclusion criterion, and a pregnancy serum test was done on all premenopausal women. A suitable method of birth control was discussed with the subject for use between studies. The protocol was approved by the Institutional Research Board, and informed consent was obtained from each subject.

\section{Test Meals}

The standard meal for gastric emptying studies at our institution consists of 1 packet of instant oatmeal (Quaker Oats Co.) reconstituted with water, mixed with $18.5 \mathrm{MBq}$ $(0.5 \mathrm{mCi})$ of ${ }^{99 \mathrm{~m} T c}$-sulfur colloid, and heated in a microwave oven. The meal has a caloric content of $100 \mathrm{kcal}$ and contains $2 \mathrm{~g}$ of fat, $4 \mathrm{~g}$ of protein, and $19 \mathrm{~g}$ of carbohydrate. In addition, the subject was allowed 1 packet of natural sugar or artificial sweetener

\section{Gastric Emptying Imaging Protocol}

After an overnight fast, the subject was instructed to eat the test meal promptly. Imaging began when the subject finished ingesting the meal. With the subject standing, serial 1-min 128 by 128 digital images were acquired initially and every $15 \mathrm{~min}$ through $60 \mathrm{~min}$ in the LAO, right posterior oblique (RPO), anterior, and posterior projections. The subject was allowed to sit between image acquisitions. The retest gastric emptying study was performed $1 \mathrm{~d}$ after the initial test.

\section{Analysis of Gastric Emptying Studies}

A region of interest was manually placed over the stomach in each image. The counts per region of interest in each image were corrected for radioactive decay. The data points were connected by straight lines. A simple halftime of gastric emptying was defined as the time when the curve reached half the counts of the gastric region of interest in the initial image.

\section{Statistical Analysis}

The $t$ test was used to test the significance of quantitative differences between groups, and the correlation coefficient was used to test the correlation between paired quantitative parameters.

\section{RESULTS}

\section{Subject Statistics}

The statistical analysis of age, height, weight, and BMI for all subjects is shown in Table 1. Men were taller and heavier than women $(P<0.01)$. All BMIs were within the required range, and BMI did not significantly differ between men and women. All 4 of the women in the 60to 80 -y age group and 1 of the women in the 40- to 60-y age group were postmenopausal and were not taking hormone replacement therapy.

\section{Gastric Emptying Studies}

A strong correlation was found among half-times of emptying calculated from the anterior projection, LAO projection, anterior-posterior geometric mean, and LAORPO geometric mean (all $P<0.01$ ). Because half-times of emptying are usually calculated from either the LAO projection or the anterior-posterior geometric mean, only the data from these 2 methods are shown in Tables 2-4 (8). A

TABLE 1

Subject Demographics

\begin{tabular}{|c|c|c|c|c|c|c|c|c|c|}
\hline \multirow[b]{2}{*}{ Sex and age category } & \multirow[b]{2}{*}{$n$} & \multicolumn{2}{|c|}{ Age (y) } & \multicolumn{2}{|c|}{ Height (cm) } & \multicolumn{2}{|c|}{ Weight (kg) } & \multicolumn{2}{|c|}{ BMI } \\
\hline & & Mean \pm SD & Range & $\overline{M e a n} \pm \mathrm{SD}$ & Range & Mean \pm SD & Range & Mean \pm SD & Range \\
\hline \multicolumn{10}{|l|}{ Men } \\
\hline $20-40$ y & 4 & $32.5 \pm 5.3$ & $27-38$ & $177 \pm 8.0$ & $165-183$ & $71.6 \pm 11.8$ & $59-86$ & $22.9 \pm 2.9$ & $19.7-26.6$ \\
\hline $40-60$ y & 4 & $46.8 \pm 4.7$ & $42-53$ & $182 \pm 8.1$ & $175-191$ & $85.4 \pm 10.0$ & $82-100$ & $26.0 \pm 1.9$ & $23.7-28.0$ \\
\hline $60-80$ y & 4 & $73.0 \pm 6.3$ & $65-80$ & $177 \pm 3.6$ & $173-180$ & $79.2 \pm 9.1$ & $70-91$ & $25.3 \pm 2.6$ & $22.9-28.0$ \\
\hline All & 12 & - & - & $179 \pm 6.7$ & $165-191$ & $78.7 \pm 11.1$ & $59-100$ & $24.7 \pm 2.7$ & $19.7-28.0$ \\
\hline \multicolumn{10}{|l|}{ Women } \\
\hline $20-40 y$ & 4 & $27.3 \pm 7.9$ & 22-39 & $167 \pm 6.3$ & $160-175$ & $59.5 \pm 10.3$ & $49-73$ & $21.3 \pm 3.1$ & $19.1-25.9$ \\
\hline $40-60$ y & 4 & $47.0 \pm 7.0$ & $41-56$ & $163 \pm 5.5$ & $158-170$ & $61.5 \pm 5.5$ & $54-66$ & $22.3 \pm 1.9$ & $20.4-26.4$ \\
\hline $60-80$ y & 4 & $63.5 \pm 2.7$ & $60-66$ & $162 \pm 3.6$ & $158-165$ & $65.8 \pm 4.8$ & $59-70$ & $25.0 \pm 1.6$ & $23.6-27.3$ \\
\hline All & 12 & - & - & $164 \pm 5.3$ & $158-175$ & $62.3 \pm 7.1$ & $49-73$ & $23.2 \pm 2.8$ & $19.1-27.3$ \\
\hline
\end{tabular}


TABLE 2

Reference Range and Reproducibility of Half-Times of Gastric Emptying as Function of Age and Sex

\begin{tabular}{|c|c|c|c|c|c|c|c|c|}
\hline \multirow[b]{3}{*}{ Sex and age category } & \multicolumn{4}{|c|}{ Reference range $(\mathrm{min})^{*}$} & \multicolumn{4}{|c|}{ Reproducibility (min) } \\
\hline & \multicolumn{2}{|l|}{ LAO } & \multicolumn{2}{|l|}{ A-P } & \multicolumn{2}{|l|}{ LAO } & \multicolumn{2}{|l|}{ A-P } \\
\hline & Mean \pm SD & Range & Mean \pm SD & Range & Mean \pm SD & Range & Mean \pm SD & Range \\
\hline \multicolumn{9}{|l|}{ Men } \\
\hline $20-40$ y & $38.0 \pm 21.0$ & $20-60$ & $35.6 \pm 22.6$ & $13-56$ & $25 \pm 8.7$ & $4-27$ & $16.6 \pm 10.6$ & $8-31$ \\
\hline $40-60$ y & $15.3 \pm 6.5$ & $9-24$ & $18.4 \pm 6.8$ & $12-26$ & $5.8 \pm 3.2$ & $2-10$ & $2.9 \pm 3.7$ & $1-8$ \\
\hline $60-80 y$ & $13.8 \pm 3.9$ & $9-18$ & $17.6 \pm 1.8$ & $16-20$ & $10.1 \pm 6.1$ & $4-18$ & $5.4 \pm 5.6$ & $0-13$ \\
\hline All & $22.3 \pm 16.5$ & $9-60$ & $23.9 \pm 15.1$ & $12-56$ & $11.0 \pm 8.2$ & $2-27$ & $8.3 \pm 9.0$ & $0-31$ \\
\hline \multicolumn{9}{|l|}{ Women } \\
\hline $20-40$ y & $28.5 \pm 9.4$ & $22-42$ & $27.9 \pm 12.3$ & $18-46$ & $8.5 \pm 10.3$ & $3-24$ & $14.6 \pm 13.8$ & $6-35$ \\
\hline $40-60$ y & $36.5 \pm 7.7$ & $28-44$ & $35.8 \pm 7.0$ & $26-42$ & $12.3 \pm 7.7$ & $1-18$ & $9.8 \pm 7.1$ & $2-18$ \\
\hline $60-80 y$ & $22.4 \pm 5.0$ & $16-26$ & $21.8 \pm 4.8$ & $15-26$ & $9.5 \pm 7.0$ & $2-18$ & $5.0 \pm 5.2$ & $1-13$ \\
\hline All & $29.1 \pm 9.2$ & $16-44$ & $28.3 \pm 10.1$ & $15-46$ & $10.1 \pm 7.8$ & $1-24$ & $9.8 \pm 9.5$ & $1-35$ \\
\hline Both men and women, all age categories & $25.7 \pm 13.5$ & $9-60$ & $26.2 \pm 12.7$ & $12-56$ & $10.5 \pm 7.9$ & $1-27$ & $9.0 \pm 9.1$ & $0-35$ \\
\hline
\end{tabular}

${ }^{*}$ Determined from first of 2 studies in each subject.

$\mathrm{A}-\mathrm{P}=$ anterior-posterior.

significant inverse correlation was found between increasing age and decreasing half-time of emptying in both men and women $(P<0.05)$. The correlation coefficients in the LAO and anterior-posterior projections were -0.52 and -0.43 for men and -0.48 and -0.59 for women. There was a non-statistically significant trend for half-times of emptying to be longer for women than for men. A large variation was found between the first and second studies in both sexes, with a trend toward decreasing variation between studies with increasing age. Proposed reference ranges for half-time of gastric emptying and reproducibility in the 3 age groups are presented in Table 4. The proposed reference range for each age group was derived from a consideration of the actual values of both the mean \pm 2 SDs and the range.

\section{DISCUSSION}

This study delineated the reference range and reproducibility of the half-time of gastric emptying using instant oatmeal as the test meal. Instant oatmeal as a test meal has the advantages of being easy to prepare and acceptable to most patients (9). In addition, oatmeal has the advantage of being a semisolid, thus minimizing the time that the patient spends masticating and, therefore, the time over which the meal enters the stomach (10). The adherence of a similar colloid label to oatmeal in gastric juice in vitro has been found to be satisfactory, at $82 \%-97 \%$ (11). And there is a relatively high correlation between the results with oatmeal and the more difficult-to-prepare scrambled egg (7).

We used the upright position because it is more physiologic than the supine or semisupine position. The subjects were allowed to sit between image acquisitions, which were performed every $15 \mathrm{~min}$. In addition, we calculated the gastric half-time of emptying by simply connecting the every-15-min data points, because the shape of the gastric emptying curve varies from patent to patient. Some of this variation may result from variable overlap of the stomach and the jejunum among patients (7).

It is essential to determine the reference limits for clinical tests. There has been 1 previous report of a reference range for gastric emptying using a test meal of oatmeal, but it was performed with non-commercially available oatmeal, in the supine position, with a noncommercially available ${ }^{99 \mathrm{~m}} \mathrm{Tc}-$ colloid, and using a nonrigo-

TABLE 3

Reference Range and Reproducibility of Half-Times of Gastric Emptying for Men and Women Combined

\begin{tabular}{|c|c|c|c|c|c|c|c|c|}
\hline \multirow[b]{3}{*}{ Age category } & \multicolumn{4}{|c|}{ Reference range $(\mathrm{min})^{\star}$} & \multicolumn{4}{|c|}{ Reproducibility (min) } \\
\hline & \multicolumn{2}{|c|}{ LAO } & \multicolumn{2}{|c|}{ A-P } & \multicolumn{2}{|c|}{ LAO } & \multicolumn{2}{|c|}{ A-P } \\
\hline & Mean \pm SD & Range & Mean $\pm S D$ & Range & Mean \pm SD & Range & Mean \pm SD & Range \\
\hline $20-40$ y & $33.3 \pm 15.9$ & $20-60$ & $31.8 \pm 17.4$ & $13-56$ & $12.8 \pm 10.8$ & $4-27$ & $15.6 \pm 11.5$ & $8-35$ \\
\hline $40-60$ y & $25.8 \pm 13.2$ & $9-44$ & $27.1 \pm 11.3$ & $12-42$ & $9.0 \pm 6.5$ & $1-18$ & $6.3 \pm 6.4$ & $0-18$ \\
\hline $60-80$ y & $18.1 \pm 6.2$ & $9-26$ & $19.7 \pm 4.0$ & $15-26$ & $9.8 \pm 6.1$ & $2-18$ & $5.2 \pm 5.0$ & $0-13$ \\
\hline
\end{tabular}

${ }^{*}$ Determined from first of 2 studies in each subject.

$\mathrm{A}-\mathrm{P}=$ anterior-posterior. 
TABLE 4

Proposed and (Actual) Reference Limits for Men and Women Combined

\begin{tabular}{lrrrrr}
\hline & \multicolumn{2}{c}{$\begin{array}{c}\text { Reference range } \\
(\mathrm{min})^{*}\end{array}$} & & \multicolumn{2}{c}{$\begin{array}{c}\text { Reproducibility } \\
(\mathrm{min})\end{array}$} \\
Parameter & LAO & A-P & & LAO & A-P \\
\hline 20-40 y & & & & \\
Proposed & $10-60$ & $10-60$ & & $\leq 30$ & $\leq 30$ \\
Mean \pm 2 SDs & $0-62$ & $0-67$ & & $0-34$ & $0-39$ \\
Range & $20-60$ & $13-56$ & & $4-27$ & $8-35$ \\
40-60 y & & & & & \\
Proposed & $10-40$ & $10-40$ & & $\leq 20$ & $\leq 20$ \\
Mean \pm 2 SDs & $0-52$ & $0-50$ & & $0-22$ & $0-19$ \\
Range & $9-44$ & $12-42$ & & $1-18$ & $0-18$ \\
60-80 y & & & & & \\
Proposed & $10-30$ & $10-30$ & & $\leq 15$ & $\leq 15$ \\
Mean \pm 2 SDs & $0-30$ & $0-28$ & & $0-22$ & $0-15$ \\
Range & $9-26$ & $15-26$ & & $2-18$ & $0-13$ \\
& & & & &
\end{tabular}

${ }^{*}$ Determined from first of 2 studies in each subject. $\mathrm{A}-\mathrm{P}=$ anterior-posterior.

rous method of determining the reference range $(12,13)$. We propose a reference range for instant oatmeal that is the same for men and women and decreases with age (Table 4). The values were rounded to a nearby decile to make the results easier to remember. Tougas et al. also found that at 1 $\mathrm{h}$, gastric emptying time decreased with increasing age in both men and women, but the same did not hold true at $4 \mathrm{~h}$ (4).

Previous studies have found a significant difference in gastric emptying between men and women. In a comparison of relatively young men and women using a meal of liver pâté, beef stew, and orange juice, the half-time of gastric emptying was approximately 50\% longer in women for both the solid phase and the liquid phase (10). The longer emptying time in women has been attributed to the female hormones estradiol and progesterone (13). Although we found a trend toward a longer half-time of gastric emptying in women than in men, the trend was not significant. However, all 4 of our female subjects in the 60- to 80-y age group and 1 female subject in the 40- to 60-y age group were postmenopausal and were not taking hormone replacement therapy. Previous studies have not found the phase of the menstrual cycle to have an effect on gastric emptying, and we did not control for this factor $(14,15)$.

It is important to determine the test-retest reproducibility of a protocol, as well as the reference range. Our results showed a trend toward decreasing variability with increasing age for an oatmeal meal. Combining the results for testretest differences in the present study based on mean \pm 2 SDs and the range, and applying a small amount of rounding, gives upper limits for between-test variation that are half the upper limit of normal for half-time of gastric emptying for each age group (Table 4). A relatively high testretest variation has been found with other meals, including a meal of ham, egg, butter, toast, and orange juice and a meal of beef stew and orange juice $(16,17)$. Although the reference range for the Tougas meal has been well documented, the test-retest reproducibility has not been established (4).

The main limitation of this study is the limited number of subjects in each age and sex category. However, statistically significant findings were demonstrated with respect to decreasing half-time of emptying with age and the correlation of results from various imaging projections. Additional studies to confirm and expand our findings would be helpful.

In comparison to the Tougas protocol, which has recently been recommended as the standard by the American Neurogastroenterology and Motility Society and the Society of Nuclear Medicine, the instant oatmeal protocol presented here has the advantages of simple preparation of the test meal, acceptability of the meal by a large percentage of the population, use of a semisolid meal that allows prompt ingestion, and a relatively short acquisition time of $60 \mathrm{~min}$, which minimizes use of nuclear medicine resources and makes it unlikely that the radioactive meal will pass through the small intestine and right colon to reenter the gastric region of interest before the end of the study (5-7). In addition, there is evidence that the information content is similar between the instant oatmeal meal and a meal consisting of an egg, which is the main ingredient of the Tougas meal (7). However, comparing the accuracy of any 2 protocols is problematic because there is no independent reference standard.

\section{CONCLUSION}

Our findings indicate that the half-time of emptying using a simple meal of instant oatmeal decreases with the age of the subject for both men and women. The test-retest reproducibility is relatively poor and tends to decrease with age. Our proposed readily useable reference ranges for halftimes of gastric emptying and reproducibility are based on consideration of the mean \pm 2 SDs and the observed range for each of the 3 age groups.

\section{ACKNOWLEDGMENT}

Financial support was provided by Talofa Foundation, Denver, Colorado.

\section{REFERENCES}

1. Griffith GH, Owen GM, Kirkman S, Shields R. Measurement of rate of gastric emptying using chromium-51. Lancet. 1966;1(7449):1244-1245.

2. Malmud LS, Fisher RS, Knight L, Rock E. Scintigraphic evaluation of gastric emptying. Semin Nucl Med. 1982;12:116-126.

3. Datz FL. Considerations for accurately measuring gastric emptying. $\mathrm{J} \mathrm{Nucl} \mathrm{Med}$. 1991;32:881-884.

4. Tougas G, Eaker EY, Abell TL, et al. Assessment of gastric emptying using a low fat meal: establishment of international control values. Am J Gastroenterol. 2000;95:1456-1462. 
5. Abell TL, Camilleri M, Donohoe K, et al. Consensus recommendations for gastric emptying scintigraphy: a joint report of the American Neurogastroenterology and Motility Society and the Society of Nuclear Medicine. J Nucl Med Technol. 2008;36:44-54.

6. Abell TL, Camilleri M, Donohoe K, et al. Consensus recommendations for gastric emptying scintigraphy: a joint report of the American Neurogastroenterology and Motility Society and the Society of Nuclear Medicine. Am J Gastroenterol. 2008;103:753-763.

7. Klingensmith WC, Lawrence SP. The gastric emptying study: protocol design considerations. J Nucl Med Technol. 2008;36:195-199.

8. Ford PV, Kennedy RL, Vogel JM. Comparison of left anterior oblique, anterior and geometric mean methods for determining gastric emptying times. J Nucl Med. 1992;33:127-130.

9. Leb G, Lipp R. Criteria for labeled meals for gastric emptying studies in nuclear medicine. Eur J Nucl Med. 1993;20:185-186.

10. Datz FL, Christian PE, Moore J. Gender-related differences in gastric emptying. J Nucl Med. 1987;28:1204-1207.

11. Fitzpatrick ML, Alderson AM. Solid food label for measurement of gastric emptying. Br J Radiol. 1979;52:920-921.
12. Digenis GA, Beihn RM, Theodorakis MC, Shambhu MB. Use of Tc-99mlabeled triethylenetetramine-polyrene resin for measuring the gastric emptying rate in humans. J Pharm Sci. 1977;66:442-443.

13. Domstad PA, Kim EE, Coupal JJ, et al. Biologic gastric emptying time in diabetic patients, using Tc-99m-labeled resin-oatmeal with and without metoclopramide. J Nucl Med. 1980;21:1098-1100.

14. Gryback P, Hemansson G, Lyrenas E, et al. Nationwide standardisation and evaluation of scintigraphic gastric emptying: reference values and comparisons between subgroups in a multicentre trial. Eur J Nucl Med. 2000;27: 647-655.

15. Horowitz M, Maddern GJ, Chatterton BE, et al. The normal menstrual cycle has no effect on gastric emptying. Br J Obstet Gynaecol. 1985;92:743-746.

16. Lartigue S, Bizais Y, Bruley des Varannnes S, Murat A, Pouliquen B, Galmiche JP. Inter- and intrasubject variability of solid and liquid gastric emptying parameters: a scintigraphic study in healthy subjects and diabetic patients. Dig Dis Sci. 1994;39:109-115.

17. Brophy CM, Moore JG, Christian PE, Egger MJ, Taylor AT. Variability of gastric emptying measurements in man employing standardized radiolabeled meals. Dig Dis Sci. 1986;31:799-806. 